\section{Monsanto defends itself}

SIR - The main thesis of the Commentary by Millstone et al. ${ }^{1}$ is that Monsanto has suppressed information on the real change in somatic cell content (SCC) of milk from bovine somatotropin (bST)supplemented cows and that this has public-health implications. The authors contend that they were justified in trying to publish an analysis of Monsanto's data without permission from the scientists who gathered the data.

Science is a self-correcting institution striving to find truth based on published data. The truth in this case is that the impact of bST on SCC of cow's milk has been widely published ${ }^{2-8}$ by university, government and corporate scientists. Moore and Hutchinson ${ }^{4}$ reported that 18 of 20 published studies measured a slight decrease or no change in SCC of milk from bST-supplemented cattle and two showed a slight increase. Thomas et al. ${ }^{7}$ summarized data from 15 US commercial herds demonstrating no effect of bST on SCC of milk. Monsallier ${ }^{3}$ reported that SCC of milk was not affected from 19 French commercial herds using Monsanto's bST formulation and three French research trials using Eli Lilly's bST formulation. McClary et al. ${ }^{2}$ published data on six research studies using Eli Lilly's bST formulation and reported a slight increase in SCC of milk from bST-supplemented cows. The papers cited represent data on more than 5,000 dairy cows from 77 individual studies in peer-reviewed articles, hardly a suppression of the facts. This literature was not mentioned in ref. 1 .

The SCC data from Monsanto studies were submitted to the Committee for Veterinary Medicinal Products (CVMP) of the European Union as well as the Center for Veterinary Medicine (CVM) of the Food and Drug Administration (FDA) in the United States. The CVM also conducted a public hearing on mastitis incidence in bST-supplemented cows (31 March 1993) where the Monsanto data were again reviewed by the FDA. The FDA and the CVMP are the appropriate regulatory authorities for evaluation of human and animal safety. These organizations have carried out their own analysis and review of the data, and both concluded that bST is safe for use in lactating dairy cows to increase milk production. Further, the entire dataset from all Monsanto studies is published in ref. 8 . All the individual studies were published separately or, in the case of the clinical trials, as a group in several journals, and these are referenced in ref. 8 . In our view, these

Letters submitted for Correspondence should be typed, double-spaced, on one side of the paper only. data and the published conclusions of the appropriate regulatory bodies do not support a public-health risk from milk derived from bST-supplemented cows.

\section{Robert J. Collier}

Douglas L. Hard

The Agricultural Group,

Monsanto,

700 Chesterfield Parkway North,

St Louis, Missouri 63198, USA

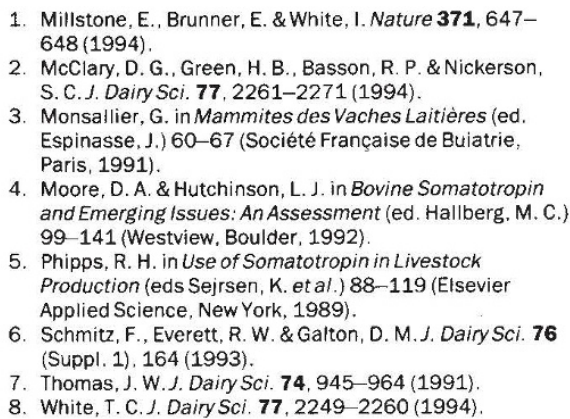

1. Millstone, E., Brunner, E. \& White, I. Nature 371, 647$648(1994)$

2. McClary, D. G., Green, H. B., Basson, R. P. \& Nickerson, S. C. J. Dairy Sci. 77, 2261-2271 (1994)

3. Monsallier, G. in Mammites des Vaches Laitières (ed Espinasse, J.) 60-67 (Société Française de Buiatrie, Paris, 1991)

4. Moore, D. A. \& Hutchinson, L. J. in Bovine Somatotropin and Emerging Issues: An Assessment (ed. Hallberg, M. C.) 99-141 (Westview, Boulder, 1992)

5. Phipps, R. H. in Use of Somatotropin in Livestock Production (eds Sejrsen, K. et al.) 88-119 (Elsevier Applied Science, New York, 1989).

6. Schmitz, F., Everett, R. W. \& Galton, D. M. J. Dairy Sci. 76 (Suppl. 1), 164 (1993).

7. Thomas, J.W.J. Dairy Sci. 74, 945-964 (1991).

8. White, T. C. J. Dairy Sci, 77, 2249-2260 (1994).

\section{A matter of degree}

SIR - In a News item about Dutch proposals to introduce short degrees $(\mathrm{Na}$ ture 371, 95; 1994), it is stated that this will be a first for mainland Europe. Some years ago, however, Denmark took this step, although without the draconian financial cuts envisaged by the Dutch.

Until then, the first degree in Denmark was equivalent to a master's, taking between five and seven years, several of which were spent in research. The then Minister of Education, Bertil Haarder, introduced the bachelor three-year degree despite protests from academics, industrialists and schoolteachers. Opponents claimed that those with bachelors' degrees would be unemployable, and this has largely proved true. There has been so much resistance by the universities that very few students take this degree if they can avoid it. The Dutch government should think again about this proposal, which may become an embarrassment, as it did here in Denmark.

\section{Dieter Britz}

Department of Chemistry,

Århus University,

DK-8000Århus C, Denmark

\section{Wrong policy?}

SIR - In a recent leading article on genome databases (Nature 371, 363; 1994) you comment: "The fear that this asymmetry [between the contributions to and uses of databases by industrial and academic scientists] would become a problem is partly why Nature resolved . . . not to make the submission of sequences to the databanks ... a condition of publication. It is naive of the research community not to have shared that caution."

This statement is a self-serving and somewhat pompous defence of an unusual (compared with other first-rate scientific journals) policy on Nature's part that only exacerbates the problem. As a scientific community, we must strive to establish a balance between competition and cooperation that best fosters progress. The pressures leading to competitive sequestration of data are intrinsic and strong within both academic institutions and industry. One would hope that the major journals and funding agencies would, for the greater benefit of the whole, strive to provide counterbalancing forces that favour cooperation and data sharing. Most do. Obviously journals that do not participate in this convention gain individual advantage by obtaining manuscripts from less altruistic members of the community. But, this is at the expense of the community as a whole.

David Shalloway

Section of Biochemistry,

Molecular and Cell Biology,

Cornell University,

Ithaca, New York 14853, USA

\section{Blanket coverage}

SIR - The recent article "HGS seeks exclusive option on all patents using its cDNA sequences" (Nature 371, 463; 1994) has stimulated us to announce the formation of our new institute, the Random Genome Research Institute (RGRI). The efforts of RGRI will soon make the interesting battle of the pharmaceutical giants over cDNA sequences irrelevant. We have gone to considerable trouble to generate all possible cDNA sequences of 2,000 bases in length. Our extensive sequence generating project will give us access to all patentable cDNA before conventional sequencing can be done. We do not intend to infringe the patent rights of those investigators who can prove the possession of sequence data before our public announcement. Sequences that contain segments from our database will also be covered in our patent application. After exercising our exclusive option for any sequence, we will gladly discuss terms for collaborations and licences on any patented sequences. Profits from RGRI will be used to fund new efforts in biological research to understand how our sequences can be combined to create organisms.

\section{Kevin Ainger}

Youhe Gao

YilongSun

RGRI, c/o Department of Biochemistry, University of Connecticut Health Center. Farmington,

Connecticut 06030-3305, USA 